\title{
MicroRNA-936 Targets FGF2 to Inhibit Epithelial Ovarian Cancer Aggressiveness by Deactivating the PI3K/Akt Pathway [Retraction]
}

\author{
Li C, Yu S, Wu S, Ni Y, Pan Z. Onco Targets Ther. \\ 2019;12:5311-5322.
}

The Editor and Publisher of OncoTargets and Therapy wish to retract the published article. Concerns were raised over alleged image duplication in Figures 4C, 5C and 7A with similar images from unrelated articles, specifically:

- Figure 4C, panel CAOV-3 si-NC appears to have been duplicated with a similar image in Figure 5C from Yang et al, 2019 (https://doi.org/10.2147/OTT. S202309).

- Figure 4C, panel CAOV-3 si-FGF2 appears to have been duplicated with a similar image in Figure 5D from Wu et al, 2018 (https://doi.org/10.3892/or.2018. 6302).

- Figure 5C, panel SKOV3 miR-control appear to have been duplicated with a similar image in Figure 6D from Zhang et al, 2018 (https://doi.org/10.3892/or.
2018.6264) and Figure 5D from $\mathrm{Wu}$ et al, 2018 (https://doi.org/10.3892/or.2018.6302).

- Figure 7A appears to have been duplicated with a similar image in Figure 8A from Zhao et al, 2018 (https://doi.org/10.3892/ijo.2018.4576).

The authors responded to our queries but were unable to provide a satisfactory explanation for the alleged duplication and could not provide satisfactory original data for their study. The Editor advised for the article to be retracted.

Our decision-making was informed by our policy on publishing ethics and integrity and the COPE guidelines on retraction.

The retracted article will remain online to maintain the scholarly record, but it will be digitally watermarked on each page as "Retracted".

\section{Publish your work in this journal}

OncoTargets and Therapy is an international, peer-reviewed, open access journal focusing on the pathological basis of all cancers, potential targets for therapy and treatment protocols employed to improve the management of cancer patients. The journal also focuses on the impact of management programs and new therapeutic agents and protocols on patient perspectives such as quality of life, adherence and satisfaction. The manuscript management system is completely online and includes a very quick and fair peer-review system, which is all easy to use. Visit http://www.dovepress.com/ testimonials.php to read real quotes from published authors. 